The Open Civil Engineering Journal
CrossMark
Content list available at: www.benthamopen.com/TOCIEJ/
DOI: $10.2174 / 1874149501711010176$

RESEARCH ARTICLE

\title{
Utilization of Circulating Fluidized Bed Fly Ash as Pozzolanic Material
}

\author{
Kae- Long Lin ${ }^{1, *}$, Ta-Wui Cheng ${ }^{2}$, Chih-Hsuan $\mathrm{Ho}^{3}$, Yu-Min Chang ${ }^{4}$ and Kang-Wei Lo ${ }^{2}$ \\ ${ }^{I}$ Department of Environmental Engineering, National ILan University, Yilan, Taiwan \\ ${ }^{2}$ Department of Materials and Mineral Resources Engineering, National Taipei University of Technology, Taipei, \\ Taiwan \\ ${ }^{3}$ Department of Construction Engineering, Dahan Institute of Technology, No.1, Shuren St., Dahan Village, Sincheng \\ Township, Hualien, Taiwan \\ ${ }^{4}$ Institute of Environmental Engineering and Management, National Taipei University of Technology, Taipei, Taiwan
}

Received: September 26, 2016

Revised: November 17, 2016

Accepted: December 19, 2016

\begin{abstract}
A circulating fluidized bed (CFB) boiler generates energy by burning petroleum coke. Because burnt petroleum coke has a high sulfur content, limestone is added to the boiler to reduce the emittance of sulfur dioxide through desulfuration. The residue collected from the boiler is called CFB ash. CFB boilers in Taiwan can produce 328,000 tonnes of CFB fly ash per year. In this study, the pozzolanic characteristics of CFB fly ash were investigated by blending CFB fly ash and ordinary Portland cement (OPC). The CFB fly ash was mainly composed of $\mathrm{CaO}, \mathrm{SO}_{3}$, and $\mathrm{SiO}_{2}$ in concentrations of $37.8 \%, 9.2 \%$, and $2.2 \%$, respectively. The crystals of CFB fly ash contained $3 \mathrm{CaO} . \mathrm{SiO}_{2}, 2 \mathrm{CaO} . \mathrm{SiO}_{2}, \mathrm{Ca}(\mathrm{OH})_{2}, \mathrm{C}-\mathrm{S}-\mathrm{H}$ (Tobermolite), and Ettringite. The results revealed that applying the toxicity characteristic leaching procedure to CFB fly ash renders it suitable for use in blended cement. At later curing ages (90 days), the pore volumes of both the OPC and the CFB-fly-ash-blended cement pastes (CFBFABCP) decreased as the curing time increased. A possible explanation is that $\mathrm{C}_{3} \mathrm{~S}$ and $\mathrm{C}_{2} \mathrm{~S}$ were consumed to form C-S-H gel, resulting in an increase in the $\mathrm{Q}^{1}$ and $\mathrm{Q}^{2}$ groups identified by ${ }^{29} \mathrm{Si}$ Nuclear Magnetic Resonance (NMR) spectroscopy. Furthermore, the peak of the Q group decreased, but those of the $\mathrm{Q}^{1}$ and $\mathrm{Q}^{2}$ peaks increased with an increasing curing time. The pozzolanic activity of the CFBFABCP containing $10 \%$ CFB fly ash indicates that it is a suitable substitute for OPC in blended cement.
\end{abstract}

Keywords: Circulating fluidized bed, Fly ash, Pozzolanic reaction, Ettringite, Pore volume, ${ }^{29}$ Si Nuclear Magnetic Resonance.

\section{INTRODUCTION}

Circulating fluidized bed (CFB) combustion is a clean technology for coal burning, which has the advantages of adaptability to numerous fuels, high combustion efficiency, low NOx emissions, and stable operation over a wide range of load regulations [1]. CFB fly ash usually contains a high content of calcium, as both an oxide and a sulfate [2]. Numerous power stations use limestone as a sorbent for the $\mathrm{SO}_{2}$ released during coal combustion [3]. CFB fly ash differs from typical coal combustion by-products in that (1) it lacks the high content of f-CaO present in atmospheric fluidized bed combustion ash, thus preventing it from reacting vigorously with water, and lacks the high content of $\mathrm{SO}_{3}$ (usually anhydrite) present in both atmospheric fluidized bed combustion ash and pressurized fluidized bed combustion ash; (2) it consists of few spherical particles because the temperature in CFB combustion boilers (often $800-900{ }^{\circ} \mathrm{C}$ ) is lower than that in pulverized coal-fired boilers (often $1300-1500^{\circ} \mathrm{C}$ ); and (3) it self-cements $[4,5]$. CFB fly ash is potentially a valuable source of major oxides, such as $\mathrm{CaO}$ and $\mathrm{SiO}_{2}$, but technology for recovering CFB fly ash is unavailable. Approximately 800,000 tonnes of CFB fly ash has been dumped into landfills in Taiwan. Technological advancements would improve recovery and reduce the environmental impact of CFB fly ash.

* Address correspondence to this author at the Department of Environmental Engineering, National I-Lan University I-Lan 26047 Taiwan, ROC; Tel: (886)39357400 Ext 749; Fax: (886) 39364277; E-mail: kllin@niu.edu.tw 
Previous investigations have indicated that CFB fly ash along with pressured fluidized bed combustion ash or pulverized fuel ash can be used to prepare cementless concrete. Conn and Sellakumar [6] demonstrated that CFB ash can be used for construction applications that do not require highly stringent specifications, including soil stabilization, road base construction, structural filling, and synthetic aggregate production. Sheng et al. [1] investigation of the cementitious properties of fly ash produced by CFBC boilers cofiring coal and high-sulfur petroleum coke revealed that a high $f$-CaO content and a high $\mathrm{SO}_{3}$ content enhance cementitious properties; in other words, CFB fly ash is cementitious. Li et al. revealed that CFB fly ash has high pozzolanic reactivity and can be used as a cement admixture [7]. Chi et al. indicated that CFB fly ash can increase water absorption and effectively reduce initial surface absorption [3]. Additionally, CFB fly ash has a positive effect on the compressive strength, splitting tensile strength, and sulfate attack resistance of hardened, roller-compacted concrete. Previous investigations have indicated that the compressive strength of mortar comprising various combinations of coal-fired fly ash and CFB fly ash is lower than that of mortar containing Portland cement. However, coal-fired fly ash can effectively mitigate strength reduction [8].

The study focused on CFB-fly-ash-blended cement pastes (CFBFABCP), in which CFB fly ash is the cementitious material. The effects of CFB fly ash on the properties of CFBFABCP samples were investigated, and the relative influence of the CFB-fly-ash-to-cement ratio on the compressive strength and porosity of CFBFABCP samples were evaluated. Additionally, microstructural differences (degree of hydration and phase composition) among the CFBFABCP samples were examined.

\section{MATERIALS AND METHODS}

\section{Materials}

The CFB fly ash was obtained from a power plant in the Central Area of Taiwan. The CFB fly ash was homogenized; oven dried at $105^{\circ} \mathrm{C}$ for 24 hours; and then the chemical composition was characterized. The principal chemical compositions of the CFB fly ash were $37.8 \% \mathrm{CaO}, 9.2 \% \mathrm{SO}_{3}, 2.3 \% \mathrm{Al}_{2} \mathrm{O}_{3}$ and $2.18 \% \mathrm{SiO}_{2}$. The leaching concentrations of the CFB fly ash met regulatory thresholds. Therefore, they have the potential as resources used for recycling. American Society for Testing and Materials (ASTM) Type I Portland cement from the Taiwan Cement Company was used in this study. It had a specific gravity was 3.15 and its physical-chemical properties met the requirements of ASTM C150.

Table 1 presents the total metals and leaching concentrations of raw materials. The total Ni metal level of the CFB fly ash was $345 \mathrm{mg} / \mathrm{kg}$, and the second highest metal level was $36 \mathrm{mg} / \mathrm{kg}$ of $\mathrm{Pb}$. The leaching concentrations of the raw materials met regulatory thresholds. Therefore, they have the potential as resources used for recycling.

Table 1. Compressive strength development of CFB fly ash blended cement pastes.

\begin{tabular}{|c|c|c|c|c|c|}
\hline Curing Time (days) & OPC & $\mathbf{1 0} \%$ & $\mathbf{2 0} \%$ & $\mathbf{3 0 \%}$ & $\mathbf{4 0 \%}$ \\
\hline 14 & 44 & 33 & 29 & 29 & 26 \\
\hline 28 & 50 & 42 & 37 & 35 & 28 \\
\hline 60 & 52 & 48 & 41 & 36 & 35 \\
\hline 90 & 54 & 49 & 45 & 44 & 42 \\
\hline
\end{tabular}

\section{Tests Carried Out}

Pastes using the aforementioned blends were prepared with a water to binder ratio of 0.4. $25.4 \times 25.4 \times 25.4 \mathrm{~mm}$ (1 x 1 x 1 in.) test cubes were prepared according to ASTM-305, followed by a moulding process (ASTM C31-69). The specimens were then demoulded and cured in a container at 95\% humidity. After curing for 7, 14, 28, 60 or 90 days, the samples were subsequently crushed and the hydration reactions were stopped with absolute alcohol, filtrated in vacuum, washed with acetone and dried, then subjected by X-ray Diffraction, Mercury intrusion porosimetry (MIP), Differential Thermal and Thermogravimetric Analysis (DTA/TGA), Fourier-Transform Infrared (FTIR) spectrometry and ${ }^{29} \mathrm{Si}$ magic-angle spinning/nuclear magnetic resonance $\left({ }^{29} \mathrm{Si}\right.$ MAS/NMR) analyses. Mercury intrusion porosimetry is based on the principle that the intrusion volume of mercury into a porous medium depends on the applied pressure. DTA/TGA analyses of the samples were performed using a Seiko SSC Model 5000 Thermal analyzer. Dry $\mathrm{N}_{2}$ gas was used as a stripping gas and a heating rate of $0.5^{\circ} \mathrm{C}$ was used. The samples were heated from 50 to $1000^{\circ} \mathrm{C}$. FTIR spectrometry was performed using the $\mathrm{KBr}$ pellet technique (in which $1 \mathrm{mg}$ of powdered sample was mixed with $150 \mathrm{mg} \mathrm{KBr}$ ), by 
employing a Bomem DA8.3 FTIR instrument, and scanning from 2000 to $400 \mathrm{~cm}^{-1}$. The degree of hydration of Portland cement and CFBFABCP pastes were analyzed by using high resolution solid state ${ }^{29} \mathrm{Si}$ MAS/NMR techniques as follows: The increase of diamagnetic shielding to the ${ }^{29} \mathrm{Si}$ nuclei that resulted from the degree of increasing condensation from the single tetrahedral structure of the monosilicates $\left(Q^{\circ}\right)$ to the end groups $\left(Q^{1}\right)$, to the chain middle groups $\left(\mathrm{Q}^{2}\right)$, to the layers and branching sites $\left(\mathrm{Q}^{3}\right)$, and finally to the three-dimensional frameworks $\left(\mathrm{Q}^{4}\right)$, led to wellseparated and analytically useful chemical shift ranges for each type of $\mathrm{SiO}_{4}$ unit. The degree of hydration (designated as $\alpha$ ) of the cement clinkers, $\mathrm{C}_{2} \mathrm{~S}$ and $\mathrm{C}_{3} \mathrm{~S}$, can be evaluated as follows by the integral intensity of the signals at -70 ppm (Q) for both the hydrated cement paste and cement powders, i.e., I(Q) and I(Q), respectively [9, 10]:

$$
\alpha=\left[1-\frac{I\left(Q^{0}\right)}{I^{0}\left(Q^{0}\right)}\right] \times 100 \%
$$

\section{RESULTS AND DISCUSSION}

\section{Compressive Strength Development of CFB Fly Ash Blended Cement Pastes}

Table 1 shows the compressive strength development of the CFBFABCPs at the curing ages of 7, 14, 28, 60, and 90 days. The compressive strength of the ordinary Portland cement paste increased slightly with age, and the overall compressive strength was 44-54 MPa. As presented in Table 2, the compressive strengths of the CFBFABCPs were lower than that of the ordinary Portland cement paste on all curing days. The compressive strength of the ordinary Portland cement paste was inversely related to the CFB fly ash content of the mixture, although the compressive strength reduction was marginal when the CFB fly ash ratio in the mixture was high. At early curing ages, the compressive strength decreased with an increase in CFB fly ash because the pozzolanic activity of CFB fly ash was comparably lower. The compressive strength also decreased because the mixture contained less cement, thus less $\mathrm{C}_{3} \mathrm{~S}$. The reduction of $\mathrm{C}_{3} \mathrm{~S}$ slowed hydration and reduced the rate of compressive strength development in the CFBFABCP samples. At the curing age of 90 days, the ordinary Portland cement paste had the highest compressive strength (54 $\mathrm{MPa}$ ), followed (in descending order) by the CFBFABCP containing 10\%, 20\%, 30\%, and 40\% CFB fly ash (49, 45, 44 , and $42 \mathrm{MPa}$, respectively). The results also revealed that when the CFBFABCP contained $10 \%-40 \% \mathrm{CFB}$ fly ash, the corresponding compressive strength decreased by 5.6\%-22.2\%. Compressive strength development increased at later ages in the CFBFABCP samples than in the ordinary Portland cement pastes, particularly at higher concentrations of CFB fly ash. The decrease in compressive strength resulted from the reduction of the cement content of the mixture and excessive production of $\mathrm{Ca}(\mathrm{OH})_{2}$ from the reaction of free lime with water, which is unfavorable to the mechanical properties of cement $[11,12]$.

Table 2. Weight loss of CFB fly ash blended cement pastes.

\begin{tabular}{|c|c|c|c|c|}
\hline \multirow{2}{*}{ Sample } & \multirow{2}{*}{ Curing Time (days) } & \multicolumn{3}{|c|}{ Weight Loss (\%) } \\
\hline & & $105-440^{\circ} \mathrm{C}$ & $440-580^{\circ} \mathrm{C}$ & $580-1007^{\circ} \mathrm{C}$ \\
\hline OPC & 7 & 23.22 & 8.39 & 11.83 \\
\hline $\mathrm{OPC}$ & 28 & 24.28 & 8.73 & 14.98 \\
\hline OPC & 90 & 28.68 & 12.71 & 8.42 \\
\hline $10 \%$ & 7 & 23.11 & 8.37 & 9.11 \\
\hline $10 \%$ & 28 & 25.66 & 9.14 & 12.43 \\
\hline $10 \%$ & 90 & 27.72 & 10.92 & 12.10 \\
\hline $20 \%$ & 7 & 19.90 & 7.35 & 13.65 \\
\hline $20 \%$ & 28 & 25.92 & 10.24 & 9.26 \\
\hline $20 \%$ & 90 & 26.44 & 9.47 & 12.59 \\
\hline $30 \%$ & 7 & 23.28 & 10.09 & 8.18 \\
\hline $30 \%$ & 28 & 24.94 & 9.24 & 13.13 \\
\hline $30 \%$ & 90 & 26.12 & 9.27 & 16.17 \\
\hline $40 \%$ & 7 & 23.70 & 8.99 & 11.71 \\
\hline $40 \%$ & 28 & 23.83 & 6.69 & 17.76 \\
\hline $40 \%$ & 90 & 24.01 & 8.37 & 18.18 \\
\hline
\end{tabular}




\section{Thermal analysis of CFB Fly Ash Blended Cement Pastes}

TGA and differential thermogravimetry were used to monitor the hydration of the CFBFABCP samples during the 90-day of curing. For the CFBFABCP samples (Fig. 1), weight loss was observed at approximately $100-200{ }^{\circ} \mathrm{C}$. The weight loss at approximately $400-580{ }^{\circ} \mathrm{C}$ can be attributed to $\mathrm{Ca}(\mathrm{OH})_{2}[13,14]$, which was probably produced during the hydration reactions of the CFBFABCP samples. Other peaks observed for the CFBFABCP samples were located at approximately $580-1007^{\circ} \mathrm{C}$, to be attributed to the decomposition of $\mathrm{CaCO}_{3}$.

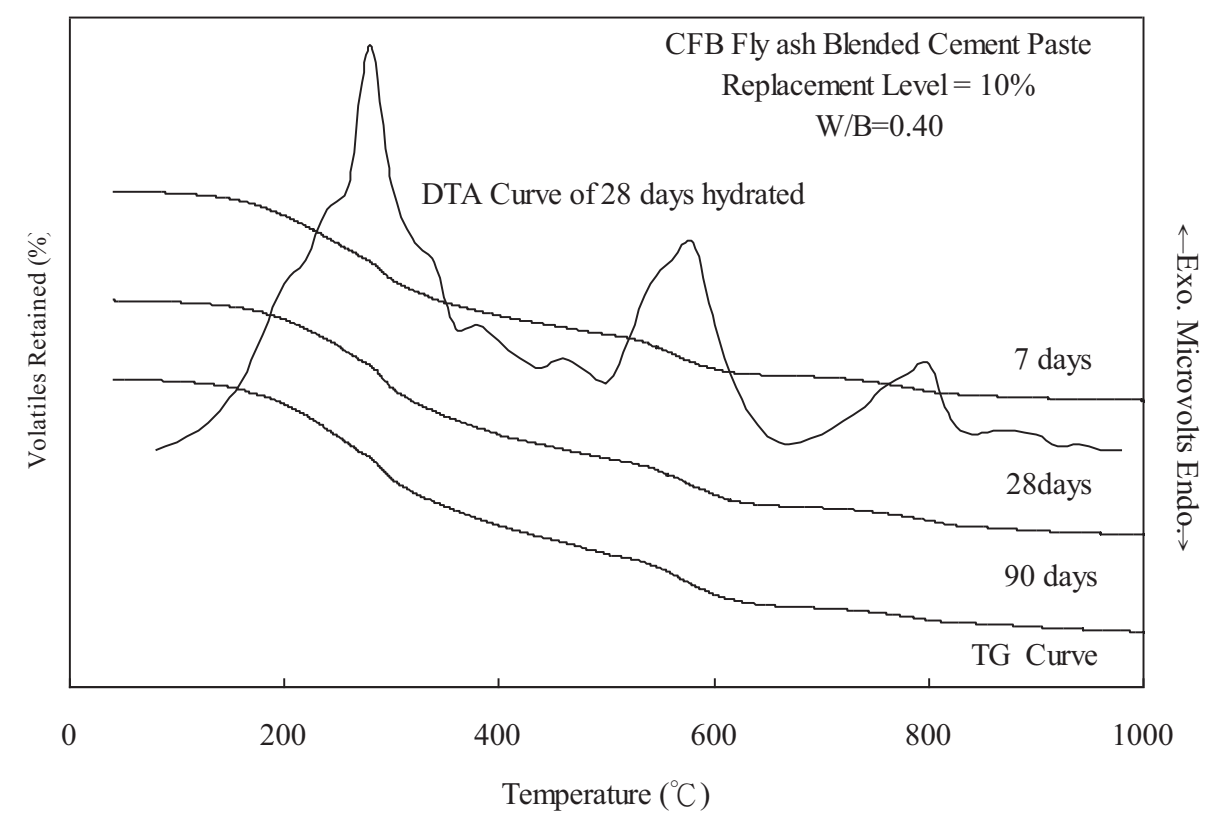

Fig. (1). TGA/DTG of CFB fly ash blended cement pastes.

As presented in Table 2, a relatively high amount of C-S-H was detected in all CFBFABCP samples. The amount of $\mathrm{C}-\mathrm{S}-\mathrm{H}$ in the CFBFABCPs increased with age. At the curing age of 28 days, the C-S-H levels were higher in the CFBFABCP containing $10 \%$ and $20 \%$ CFB fly ash $(25.66 \%$ and $25.92 \%$, respectively) than in the ordinary Portland cement paste (8.73\%). In the CFBFABCP containing 30\% and 40\% CFB fly ash, the C-S-H levels decreased as the CFB fly ash levels increased. This is usually associated with the C-S-H gel decomposition and its gradual increase indicated the increasing formation of this phase during hydration (Table 2). Conversely, the second peak at approximately $100-200^{\circ} \mathrm{C}$ can be attributed to the dehydration of the CFBFABCPs. The difference in $\mathrm{CH}$ grains possibly resulted from the hydration of the different CFBFABCP samples. The peak position of the dehydroxylation temperature of $\mathrm{Ca}(\mathrm{OH})_{2}$ was reportedly influenced by crystallite size; smaller crystals were associated with lower peak positions [15, 16]. At the curing age of 90 days, the $\mathrm{Ca}(\mathrm{OH})_{2}$ concentration in the CFBFABCP containing $10 \%, 20 \%, 30 \%$, and $40 \%$ CFB fly ash were $10.92 \%, 9.47 \%, 9.27 \%$, and $8.37 \%$, respectively, which were all lower than that of the OPC paste $(12.71 \%)$. Therefore, the concentration of $\mathrm{Ca}(\mathrm{OH})_{2}$ continually decreased as the CFB fly ash concentration was increased to $40 \%$.

\section{FTIR Spectra of CFB Fly Ash Blended Cement Pastes}

Fig. (2) illustrates the FTIR spectra of the CFBFABCP samples at various curing times. The band at a characteristic wavenumber of approximately $815-980 \mathrm{~cm}^{-1}$ decreased, indicating that alite $\left(\mathrm{Ca}_{3} \mathrm{SiO}_{5}\right)$ dissolved $[17,18]$. The peaks at $510-535,864$, and $936 \mathrm{~cm}^{-1}$ could be assigned to $\gamma-\mathrm{C}_{2} \mathrm{~S}$, whereas those at 883,903 , and $996 \mathrm{~cm}^{-1}$ could be attributed to the presence of $\beta-\mathrm{C}_{2} \mathrm{~S}$ [19]. The CFBFABCP containing 30\% and 40\% CFB fly ash displayed weak Si-O bending vibrations at early ages because the content of the $\mathrm{C}_{3} \mathrm{~S}$ mineral decreased, but $\alpha-\mathrm{C}_{2} \mathrm{~S}$ increased, as the amount of CFB fly ash increased. Thus, the hydration of $\alpha-\mathrm{C}_{2} \mathrm{~S}$ could not contribute to the Si-O bending vibrations. In addition, the poorly resolved band at around $500-750 \mathrm{~cm}^{-1}$ was attributed to $\mathrm{C}_{3} \mathrm{~A}$.

The band at a wavenumber characteristic of the $-\mathrm{OH}$ in $\mathrm{Ca}(\mathrm{OH})_{2}$ (approximately $3440-3640 \mathrm{~cm}^{-1}$ ), as well as the band at approximately 1424-1436 $\mathrm{cm}^{-1}$, was attributed to carbonate vibrations (C-O). The band at $1112 \mathrm{~cm}^{-1}$ was attributed to $v 3 \mathrm{SO}_{4}{ }^{2-}$ (sulfate) vibrations. By contrast, the band at $970-990 \mathrm{~cm}^{-1}$ was attributed to Si-O in the C-S-H gel. 
It subsequently shifted to 460,525 , and $900 \mathrm{~cm}^{-1}$, indicating $\mathrm{Si}-\mathrm{O}\left(\mathrm{C}_{3} \mathrm{~S}\right)$ bending vibrations. Water stress $(\mathrm{O}-\mathrm{H})$ and deformation $(\mathrm{H}-\mathrm{OH})$ bands became visible at approximately 3500 and $1600 \mathrm{~cm}^{-1}$, respectively. Substantial changes were observed at approximately 1100-900 $\mathrm{cm}^{-1}$ between 28 and 90 days of curing. Presumably, the band observed at approximately $950-980 \mathrm{~cm}^{-1}$ was engendered by the formation of a C-S-H gel in activated pastes. Moreover, the Si-O bending vibrations of the C-S-H gel decreased as the CFB fly ash increased. When CFB fly ash was added to the pastes, the $\mathrm{C}_{3} \mathrm{~S}$ mineral decreased, causing the $\mathrm{C}-\mathrm{S}-\mathrm{H}$ gel to decrease as well. The spectral bands of the CFBFABCP samples indicate the presence of water molecules from the crystallization or absorption of the reaction products. Moreover, changes also occurred at lower frequencies (in the range of the Si-O-Si deformation vibrations); the peak of 510-530 $\mathrm{cm}^{-1}$ shifted to $490 \mathrm{~cm}^{-1}$ and that of $580 \mathrm{~cm}^{-1}$ to about $560 \mathrm{~cm}^{-1}$ and were assigned to the deformation vibration of Si-OSi $[20-22]$.

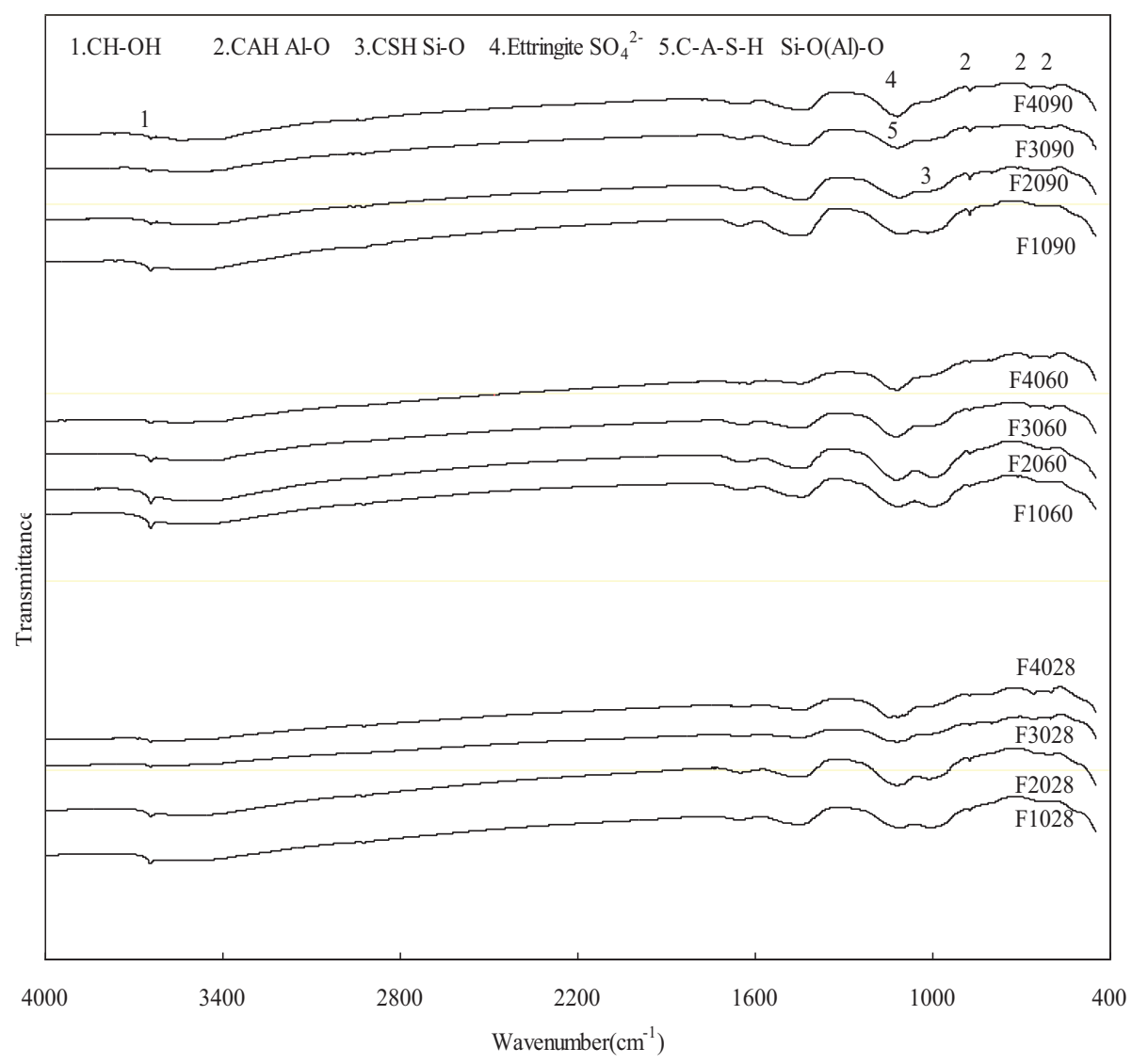

Fig. (2). FTIR spectra of the blended cement pastes at various curing times.

\section{Pore Size Distribution and Pore Volume of CFB Fly Ash Blended Cement Pastes}

Mercury intrusion porosimetry (MIP) normally underestimates porosity, because the smallest pores, and some large pores, become separated from the interconnected pore network by the smallest pores and are thus inaccessible by mercury [23]. Nevertheless, the pore distribution was measured using the MIP method and the results are presented in Fig. (3). When pore size distribution decreases with an increase of curing time. When the pore size distribution of the CFBFABCP samples decreased from 10 to $1 \mu \mathrm{m}$, the pore size distribution curves shifted toward smaller pore sizes, indicating a finer pore structure; additionally, porosity slightly increased. Moreover, at early curing ages, the pore size distribution increased with the CFB fly ash replacement level; this increase was attributed to the comparably lower pozzolanic activity of CFB fly ash. At 90 days of curing, a further reduction in pore size distribution occurred, from 1 to $0.1 \mu \mathrm{m}$. 

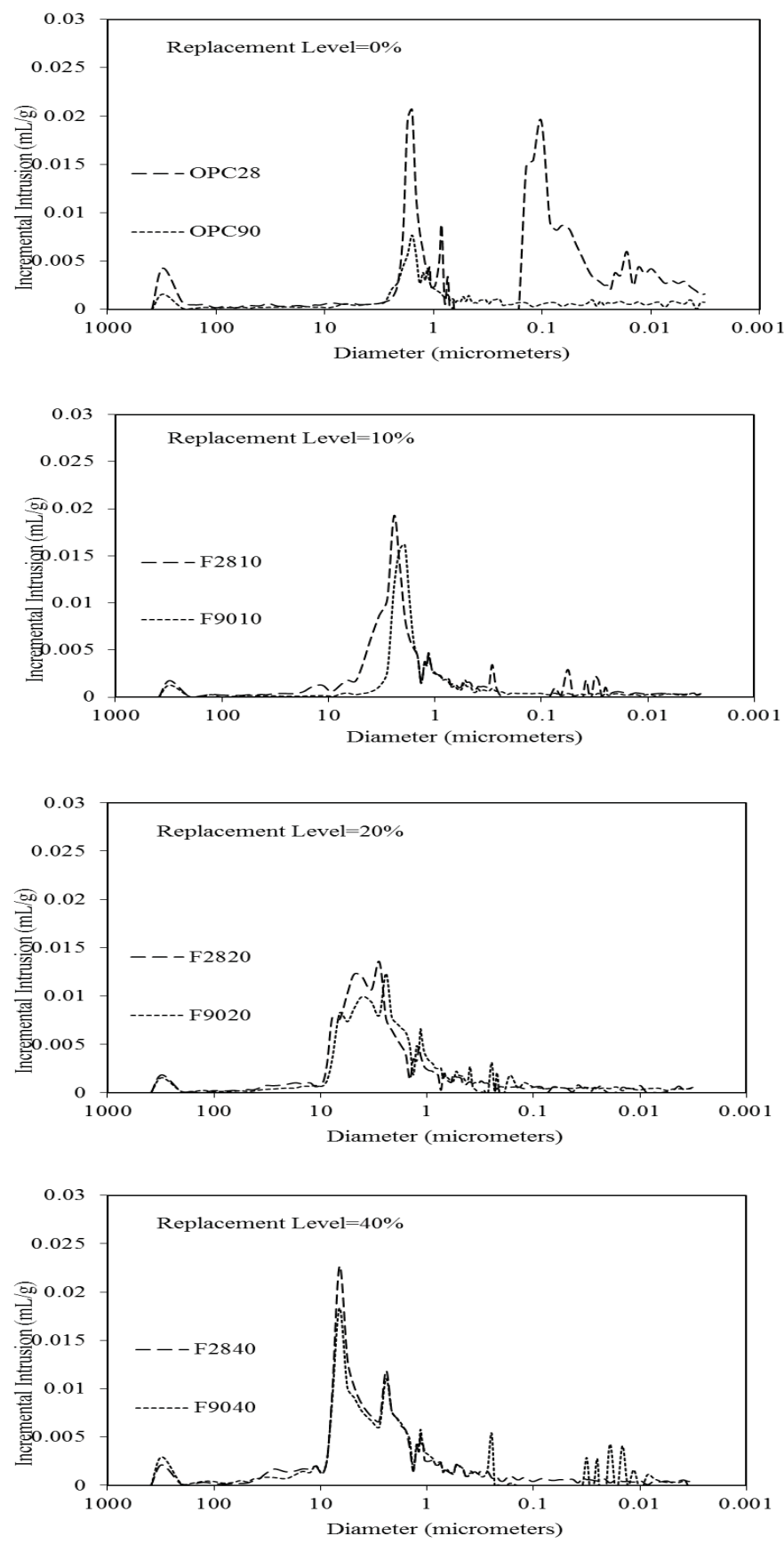

Fig. (3). Pore size distribution of CFB fly ash blended cement pastes.

Fig. (4) illustrates the pore volumes of the CFBFABCP samples at curing ages of 28 and 90 days. The observed pore volume decreased as the curing time increased. At the age of 28 days, the total pore volumes of the CFBFABCP samples containing $10 \%, 20 \%, 30 \%$, and $40 \%$ CFB fly ash were $0.176,0.191,0.211$, and $0.224 \mathrm{~mL} / \mathrm{g}$, respectively, which were all higher than that of the ordinary Portland cement paste $(0.165 \mathrm{~mL} / \mathrm{g})$. The pore volume of the CFBFABCP samples exceeded that of the ordinary Portland cement paste and increased directly with the CFBC fly ash concentration at all ages. At the age of 90 days, the total pore volumes of the CFBFABCP samples containing $10 \%$, $20 \%, 30 \%$, and $40 \%$ CFB fly ash were all higher than that of the ordinary Portland cement paste $(0.109 \mathrm{~mL} / \mathrm{g})$ at 0.136 , $0.190,0.198$, and $0.215 \mathrm{~mL} / \mathrm{g}$, respectively. The total pore volumes continually increased as the CFB fly ash concentration was increased to $40 \%$. This observation suggests that for the CFBFABCP containing $100 \%$ CFB fly ash, the hydration of the CFB fly ash particles would consume existing cement hydrates and produces new hydrates, maintaining a fairly constant porosity level while aging. 

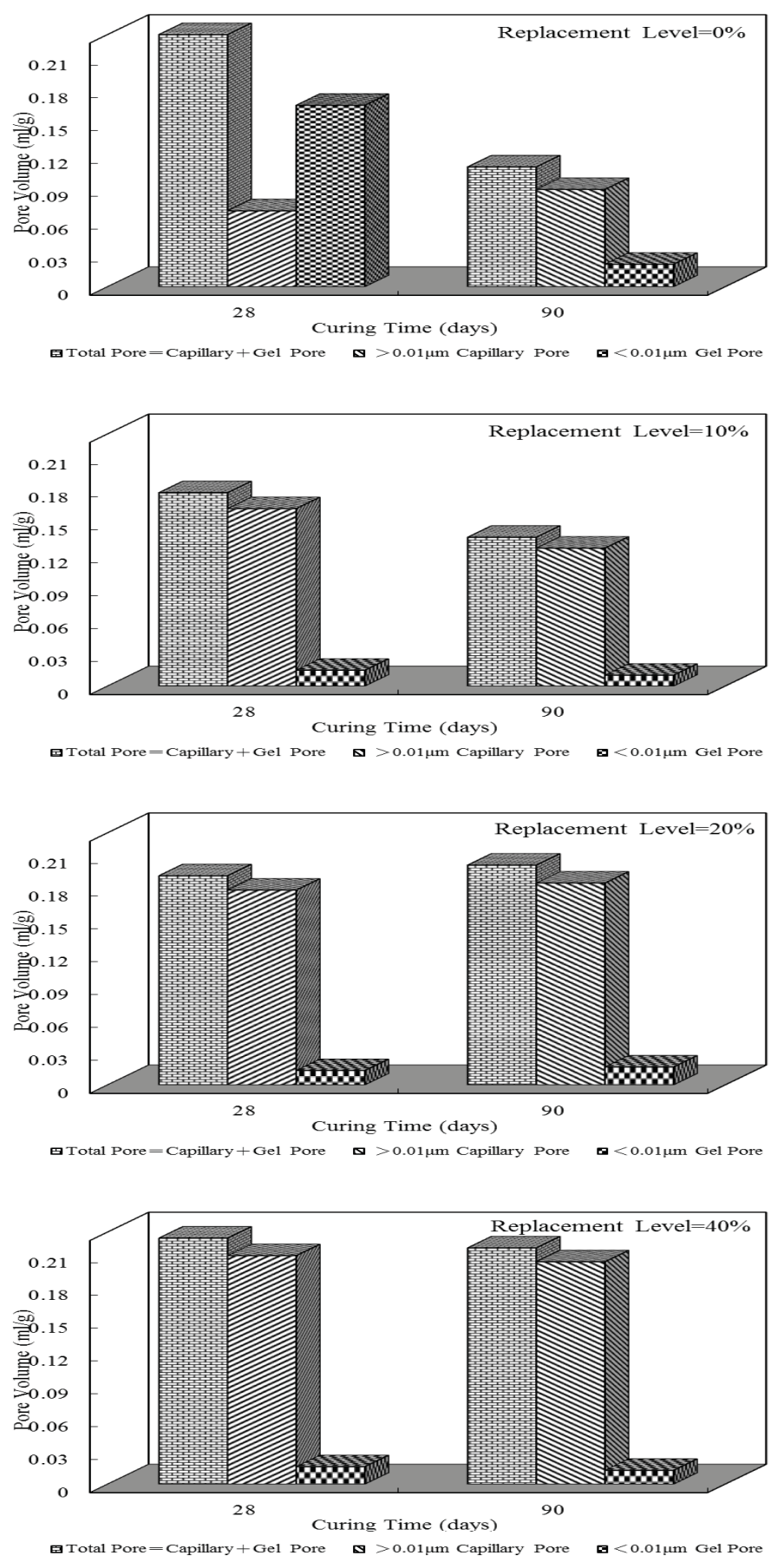

Fig. (4). Pore volume of CFB fly ash blended cement pastes.

\section{${ }^{29}$ Si MAS/NMR Spectroscopy of CFB Fly Ash Blended Cement Pastes}

Figs. (5 and 6) depict the ${ }^{29} \mathrm{Si} \mathrm{MAS/NMR} \mathrm{spectroscopy} \mathrm{of} \mathrm{ordinary} \mathrm{Portland} \mathrm{cement} \mathrm{and} \mathrm{the} \mathrm{CFBFABCP} \mathrm{containing}$ $10 \%$ CFB fly ash. As shown by the ${ }^{29} \mathrm{Si}$ NMR spectroscopy, the Q $(-70 \mathrm{ppm})$ species shifted to the $\mathrm{Q}^{1}(-80 \mathrm{ppm})$ and $\mathrm{Q}^{2}$ $(-87 \mathrm{ppm})$ species during curing [24]. As the curing time increased, the peak of the $\mathrm{Q}^{\circ}$ group decreased, whereas those of the $\mathrm{Q}^{1}$ and $\mathrm{Q}^{2}$ hydrates increased. Compared with the spectra of unreacted ordinary Portland cement, a major shift of the spectrum was detected. The ${ }^{29} \mathrm{Si}$ NMR spectroscopy showed that the $\mathrm{Q}(-70 \mathrm{ppm})$ species shifted to the $\mathrm{Q}^{1}(-80 \mathrm{ppm})$ and $\mathrm{Q}^{2}(-87 \mathrm{ppm})$ species in the CFBFABCP containing 10\% CFB fly ash, faster than that in containing $40 \%$ CFB fly ash. This is possibly because the CFBFABCP containing $10 \%$ CFB fly ash had a higher $\mathrm{C}_{3} \mathrm{~S}$ 
mineral concentration than did the CFBFABCP containing 40\% CFB fly ash, causing further production of C-S-H gel. According to these results, the conclusion was made that the mechanical strength of cement pastes obtained through alkaline activation of CFBFABCPs result from the formation of three different products, independent of curing conditions. The main reaction product is a low-crystalline calcium silicate hydrate with a dreierketten-type structure [25]. Similarly, the CFBFABCP containing 30\%-40\% CFB fly ash exhibited low transformation because the $\mathrm{C}_{3} \mathrm{~S}$ mineral content decreased, but $\beta-\mathrm{C}_{2} \mathrm{~S}$ and $\alpha-\mathrm{C}_{2} \mathrm{~S}$ increased as the amount of CFB fly ash increased. The hydration in early curing ages was mainly provided by $\mathrm{C}_{3} \mathrm{~S}$ [26], whereas the $\alpha-\mathrm{C}_{2} \mathrm{~S}$ mineral did not provide any hydration. Thus, the conversion of the $\mathrm{Q}(-70 \mathrm{ppm})$ species into the $\mathrm{Q}^{1}(-80 \mathrm{ppm})$ and $\mathrm{Q}^{2}(-87 \mathrm{ppm})$ species was slowed considerably.

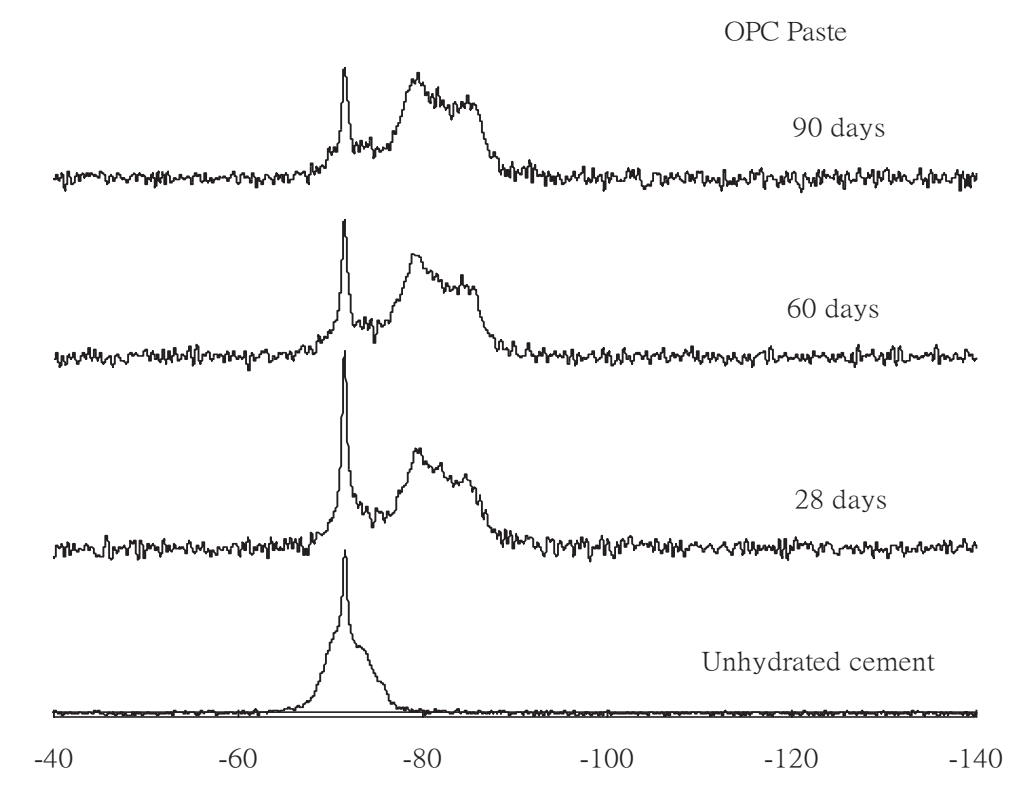

Fig. (5). ${ }^{29} \mathrm{Si}$ MAS/NMR spectra of OPC.

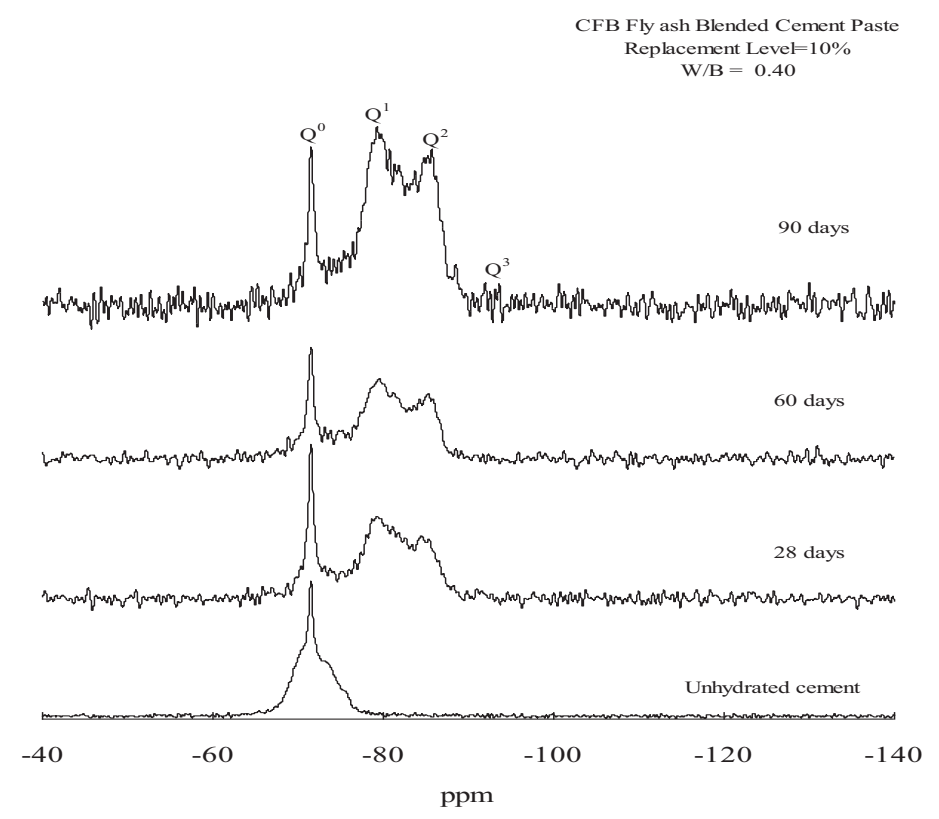

Fig. (6). ${ }^{29} \mathrm{Si}$ MAS/NMR spectra of CFBFABCP containing $10 \%$ CFB fly ash. 
Table 3 shows the degree of hydration of the CFBFABCP samples. When the CFBFABCPs contained 10\%, 20\%, $30 \%$, and $40 \%$ CFBC fly ash, the degree of hydration was $78.4 \%, 65.8 \%$, and $52.3 \%$, respectively. All the CFBFABCP samples displayed a lower degree of hydration than that of the ordinary Portland cement paste. It is obvious that the degree of hydration is able to reduce as the CFBC fly ash. The result was identical to that of the ${ }^{29} \mathrm{Si} \mathrm{MAS/NMR}$ spectroscopy. At 90 curing days, the degree of hydration of the pastes containing $10 \%, 20 \%, 30 \%$, and $40 \%$ CFBC fly ash was $78.4 \%, 65.8 \%$, and $52.3 \%$, respectively. The results obtained by ${ }^{29} \mathrm{Si} \mathrm{MAS} / \mathrm{NMR}$ confirmed that calcium silicate hydrate was a reaction product in the CFBFABCP samples.

Table 3. The degree of hydration of CFB fly ash blended cement pastes.

\begin{tabular}{|c|c|c|c|c|c|c|c|}
\hline \multirow{2}{*}{ Sample } & \multirow{2}{*}{ Curing Time (day) } & \multicolumn{4}{|c|}{${ }^{29} \mathrm{Si}$ NMR spectra } & \multirow{2}{*}{ Total } & \multirow{2}{*}{ Degree of Hydration (\%) } \\
\hline & & $\mathbf{Q}$ & $\mathbf{Q}^{1}$ & $\mathbf{Q}^{2}$ & $Q^{3}$ & & \\
\hline OPC & 28 & 363 & 326 & 253 & 59 & 1000 & 63.7 \\
\hline OPC & 60 & 315 & 382 & 265 & 38 & 1000 & 68.5 \\
\hline OPC & 90 & 295 & 374 & 287 & 44 & 1000 & 70.5 \\
\hline $10 \%$ & 28 & 352 & 339 & 259 & 50 & 1000 & 64.8 \\
\hline $10 \%$ & 60 & 326 & 376 & 274 & 24 & 1000 & 67.4 \\
\hline $10 \%$ & 90 & 253 & 381 & 322 & 44 & 1000 & 74.7 \\
\hline $20 \%$ & 28 & 408 & 313 & 235 & 44 & 1000 & 59.2 \\
\hline $20 \%$ & 60 & 316 & 362 & 288 & 34 & 1000 & 68.4 \\
\hline $20 \%$ & 90 & 307 & 349 & 305 & 40 & 1000 & 69.3 \\
\hline $30 \%$ & 28 & 393 & 314 & 238 & 55 & 1000 & 60.7 \\
\hline $30 \%$ & 60 & 310 & 351 & 298 & 41 & 1000 & 69.0 \\
\hline $30 \%$ & 90 & 307 & 345 & 306 & 41 & 1000 & 69.3 \\
\hline $40 \%$ & 28 & 396 & 315 & 234 & 55 & 1000 & 60.4 \\
\hline $40 \%$ & 60 & 316 & 351 & 283 & 50 & 1000 & 68.4 \\
\hline $40 \%$ & 90 & 307 & 325 & 308 & 60 & 1000 & 69.3 \\
\hline
\end{tabular}

\section{CONCLUSION}

The main findings of this study are summarized as follows. $\mathrm{CaO}, \mathrm{SO}_{3}$, and $\mathrm{SiO}_{2}$ were the major components observed in the CFB fly ash. For the CFBFABCP samples, the pore volume generally decreased as the curing time increased. An explanation for this observation is that at later ages (90 days), $\mathrm{C}_{3} \mathrm{~S}$ and $\mathrm{C}_{2} \mathrm{~S}$ were consumed and $\mathrm{C}-\mathrm{S}-\mathrm{H}$ gel was produced. Thus, the $\mathrm{Q}^{1}$ and $\mathrm{Q}^{2}$ hydrants increased, as identified by the ${ }^{29} \mathrm{Si}$ NMR spectroscopy. Furthermore, the peak of the $\mathrm{Q}$ group decreased, but that of the hydrates $\mathrm{Q}^{1}$ and $\mathrm{Q}^{2}$ increased with the curing time. The degree of hydration of the CFBFABCP samples was lower than that of the ordinary Portland cement paste at the age of 90 days. Finally, the pozzolanic activity of the CFBFABCP with $10 \%$ CFB fly ash indicates that it is a suitable substitute for ordinary Portland cement in blended cement.

\section{CONFLICT OF INTEREST}

The authors confirm that this article content has no conflict of interest.

\section{ACKNOWLEDGEMENTS}

Declared none.

\section{REFERENCES}

[1] G. Sheng, J. Zhai, Q. Li, and F. Li, "Utilization of fly ash coming from a CFBC boiler co-firing coal and petroleum coke in Portland cement", Fuel, vol. 86, pp. 2625-2631, 2007.

[http://dx.doi.org/10.1016/j.fuel.2007.02.018]

[2] P. Grammelis, G. Skodras, E. Kakaras, D.J. Karangelos, N.P. Petropoulos, M.J. Anagnostakis, E.P. Hinis, and S.E. Simopoulos, "Effects of biomass co-firing with coal on ash properties Part II: Leaching, toxicity and radiological behavior", Fuel, vol. 85, pp. 2316-2322, 2006. [http://dx.doi.org/10.1016/j.fuel.2006.01.035]

[3] M. Chi, and R. Huang, "Effect of circulating fluidized bed combustion ash on the properties of roller compacted concrete", Cement Concr. Compos., vol. 45, pp. 148-156, 2014.

[http://dx.doi.org/10.1016/j.cemconcomp.2013.10.001] 
[4] E.J. Anthony, E.E. Berry, J. Blondin, E.M. Bulewicz, and S. Burwell, "Advanced ash management technologies for CFBC ash", Waste Manag., vol. 23, no. 6, pp. 503-516, 2003 [http://dx.doi.org/10.1016/S0956-053X(02)00117-4] [PMID: 12909091]

[5] D. Ravikumar, S. Peethamparan, and N. Neithalath, "Structure and strength of NaOH activated concretes containing fly ash or GGBFS as the sole binder", Cement Concr. Compos., vol. 32, pp. 399-410, 2010. [http://dx.doi.org/10.1016/j.cemconcomp.2010.03.007]

[6] R.E. Conn, and K. Sellakumar, "Utilization of CFB fly ash for construction applications", In: Proceedings of the 15 ${ }^{\text {th }}$ International Conference on Fluidized Bed Combustion, 1999, pp. FBC99-0144.

[7] X. Li, Q. Chen, K. Huang, B. Ma, and B. Wu, "Cementitious properties and hydration mechanism of circulating fluidized bed combustion (CFBC) desulfurization ashes", Construct. Build. Mater., vol. 36, pp. 182-187, 2012. [http://dx.doi.org/10.1016/j.conbuildmat.2012.05.017]

[8] T. Wu, M. Chi, and R. Huang, "Characteristics of CFBC fly ash and properties of cement-based composites with CFBC fly ash and coal-fired fly ash", Construct. Build. Mater., vol. 66, pp. 172-180, 2014. [http://dx.doi.org/10.1016/j.conbuildmat.2014.05.057]

[9] K.L. Lin, K.W. Lo, J.L. Shie, B.L. Tuan, C.L. Hwang, and Y.M. Chang, "Properties and microstructure of eco-cement produced from cosintered washed fly ash and waste sludge", Environ. Prog. Sustain. Energy. in press

[10] K.L. Lin, N.F. Wang, J.L. Shie, T.C. Lee, and C. Lee, "Elucidating the hydration properties of paste containing thin film transistor liquid crystal display waste glass", J. Hazard. Mater., vol. 159, no. 2-3, pp. 471-475, 2008. [http://dx.doi.org/10.1016/j.jhazmat.2008.02.044] [PMID: 18375057]

[11] T. Wu, M. Chi, and R. Huang, "Characteristics of CFBC fly ash and properties of cement-based composites with CFBC fly ash and coal-fired fly ash", Construct. Build. Mater., vol. 66, pp. 172-180, 2014. [http://dx.doi.org/10.1016/j.conbuildmat.2014.05.057]

[12] C. Poon, L. Lam, and Y. Wong, "A study on high strength concrete prepared with large volumes of low calcium fly ash", Cement Concr. Res., vol. 30, pp. 447-455, 2000. [http://dx.doi.org/10.1016/S0008-8846(99)00271-9]

[13] L. Kriskova, Y. Pontikes, F. Zhang, Ö. Cizer, P.T. Jones, K.V. Balen, and B. Blanpain, "Influence of mechanical and chemical activation on the hydraulic properties of gamma dicalcium silicate", Cement Concr. Res., vol. 55, pp. 59-68, 2014. [http://dx.doi.org/10.1016/j.cemconres.2013.10.004]

[14] S.A. Bernal, J.L. Provis, D.G. Brice, A. Kilcullen, P. Duxson, and J.S. van Deventer, "Accelerated carbonation testing of alkali-activated binders significantly underestimates service life: the role of pore solution chemistry", Cement Concr. Res., vol. 42, pp. 1317-1326, 2012. [http://dx.doi.org/10.1016/j.cemconres.2012.07.002]

[15] H.G. Midgley, "The determination of calcium hydroxide in set Portland cements", Cement Concr. Res., vol. 9, pp. 77-82, 1979. [http://dx.doi.org/10.1016/0008-8846(79)90097-8]

[16] D.R. Johnson, and W.A. Robb, "Gaylussite: thermal properties by simultaneous thermal analysis", Am. Mineral., vol. 58, pp. 778-784, 1973.

[17] F. Puertas, and A. Fernández-Jiménez, "Mineralogical and microstructural characterization of alkali-activated fly ash/slag pastes", Cement Concr. Compos., vol. 25, pp. 287-292, 2003. [http://dx.doi.org/10.1016/S0958-9465(02)00059-8]

[18] A. Palomo, M.W. Grutzeck, and M.T. Blanco, "Alkali-activated fly ashes: A cement for the future", Cement Concr. Res., vol. 29, pp. 1323-1329, 1999.

[http://dx.doi.org/10.1016/S0008-8846(98)00243-9]

[19] L. Fernandez, C. Alonso, A. Hidalgo, and C. Andrade, "The role of magnesium during the hydration of C3S and C-S-H formation. Scanning electron microscopy and mid-infrared studies", Adv. Cement Res., vol. 17, pp. 9-21, 2005.

[http://dx.doi.org/10.1680/adcr.2005.17.1.9]

[20] I. García Lodeiro, D.E. Macphee, A. Palomo, and A. Fernández-Jiménez, "Effect of alkalis on fresh C-S-H gels. FTIR analysis", Cement Concr. Res., vol. 39, pp. 147-153, 2009. [http://dx.doi.org/10.1016/j.cemconres.2009.01.003]

[21] I.G. Lodeiro, A. Fernández-Jimenez, A. Palomo, and D.E. Macphee, "Effect on fresh C-S-H gels of the simultaneous addition of alkali and aluminium", Cement Concr. Res., vol. 40, pp. 27-32, 2010. [http://dx.doi.org/10.1016/j.cemconres.2009.08.004]

[22] S.A. Bernal, J.L. Provis, D.G. Brice, A. Kilcullen, P. Duxson, and J.S. van Deventer, "Accelerated carbonation testing of alkali-activated binders significantly underestimates service life: the role of pore solution chemistry", Cement Concr. Res., vol. 42, pp. 1317-1326, 2012. [http://dx.doi.org/10.1016/j.cemconres.2012.07.002]

[23] H. Ma, B. Xu, and Z. Li, "Magnesium potassium phosphate cement paste: Degree of reaction, porosity and pore structure", Cement Concr. Res., vol. 65, pp. 96-104, 2014. [http://dx.doi.org/10.1016/j.cemconres.2014.07.012]

[24] I.G. Richardson, A.R. Brough, G.W. Groves, and C.M. Dobson, "Characterisation of hardened alkali-activated blast furnace slag pastes and the nature of the calcium silicate hydrate (CSH)", Cement Concr. Res., vol. 5, pp. 813-829, 1994. 
[http://dx.doi.org/10.1016/0008-8846(94)90002-7]

[25] T. Bakharev, J.G. Sanjayan, and Y.B. Cheng, "Effect of elevated temperature curing on properties of alkali-activated slag concrete", Cement Concr. Res., vol. 29, no. 10, pp. 1619-1625, 1999.

[26] A. Fernández-Jiménez, J.G. Palomo, and F. Puertas, "Alkali-activated slag mortars: Mechanical strength behavior", Cement Concr. Res., vol. 29, pp. 1313-1321, 1999.

[http://dx.doi.org/10.1016/S0008-8846(99)00154-4]

\section{(C) 2017 Lin et al.}

This is an open access article distributed under the terms of the Creative Commons Attribution 4.0 International Public License (CC-BY 4.0), a copy of which is available at: https://creativecommons.org/licenses/by/4.0/legalcode. This license permits unrestricted use, distribution, and reproduction in any medium, provided the original author and source are credited. 